\title{
ANALYSIS OF THE SETTING AND PREDICTIVE FACTORS OF THE EFFECT OF ATTACK ACCORDING TO GAME ECOLOGY: THE CASE OF FEMALE VOLLEYBALL
}

\author{
Augusto Cezar Rodrigues Rocha ${ }^{1}$, Gustavo Ferreira Pedrosa ${ }^{2}$, Auro Barreiros Freire ${ }^{3}$, \\ Gibson Moreira Praça ${ }^{4}$, Herbert Ugrinowitsch ${ }^{4}$, Henrique de Oliveira Castro ${ }^{5,6}$, \\ and Gustavo de Conti Teixeira Costa ${ }^{1}$ \\ ${ }^{1}$ Universidade Federal de Goiás - UFG, Goiânia/Goiás, Brazil \\ ${ }^{2}$ Centro de Instrução e Adaptação da Aeronáutica, Lagoa Santa/Minas Gerais, Brazil \\ ${ }^{3}$ Pontifícia Universidade Católica de Minas Gerais - PUC-MG, \\ Belo Horizonte/Minas Gerais, Brazil \\ ${ }^{4}$ Universidade Federal de Minas Gerais - UFMG, Belo Horizonte/Minas Gerais, Brazil \\ ${ }^{5}$ Faculdade Anhanguera de Taguatinga Norte, Taguatinga/DF, Brasil \\ ${ }^{6}$ Centro Universitário IESB, Brasília/DF, Brasil
}

Original scientific article

DOI: $10.26582 / \mathrm{k} .52 .2 .7$

\begin{abstract}
:
The objective of this study was to identify how the ecological variables influence the setter during the setting and what were the predictive factors of the attack effect among Brazilian teams ranked from the $1^{\text {st }}$ to $4^{\text {th }}$ place in the volleyball Women's Super-League in 2016-2017. We analyzed 768 attacks from 10 matches played among the teams. A descriptive analysis was performed and, to identify how the setting location differed in relation to the ecological variables, the one-way ANOVA (factor $1=$ setting location) was used. In addition, multinomial logistic regression was performed to understand the predictive factors of the effect of the attack. The significance level was set at 5\% $(\mathrm{p} \leq .05)$ and the SPSS software version 20.0 was used. The results showed the setting location differed according to the distance between the setter and the central attacker, the distance between the setter and the central blocker, and the distance between the setter and the blocker of position 4. Besides, it was observed that the powerful attack and the blocking touch were predictive factors of the effect of the attack. Thus, it is concluded that the decision-making for the action of the setting is based on the availability of the central attacker and the configuration of the blockers, the powerful attack reduces the chances of defense and the blocking touch reduces the chances of scoring by attacking.
\end{abstract}

Key words: volleyball, game analysis, game ecology

\section{Introduction}

The observational analysis that allows understanding what are the game aspects that influence sports performance (Barreiro \& Silva, 2016; Clemente, Martins, Mendes, \& Silva, 2016) is not recent in sports (Eom \& Schutz, 1992; Hughes \& Bartlett, 2002). In the case of volleyball, it has been observed that the attack is the most researched skill, and the predictive factors of the effect of this are the fast ball setting for the $1^{\text {st }}$ and $2^{\text {nd }}$ tempo (García-deAlcaraz, Ortega, \& Palao, 2015; Mesquita, Palao, Marcelino, \& Afonso, 2013) and powerful parallel and diagonal attacks (Costa, et al., 2017b, Conti, et al., 2018). In addition, the quality of the opposing team makes it possible to manage the risk at the decision-making (Garcia-de-Alcaraz \& Marcelino,
2017), which results in changes in the type of game practiced (Costa, et al., 2017a), suggesting that situational constraints must be taken into account when analyzing a volleyball game (Paulo, Davids, \& Araújo, 2017; Ramos, et al., 2017).

In this context, the performance is a resultant of the adaptation of actions to the dynamic aspects of the game (Araújo, Davids, \& Hristovski, 2006; Davids, Araújo, \& Seifert, 2015) and interaction with the opponent lays the ecological variables (Paulo, Davids, et al., 2017). Thus, in interactions of the environment-athlete system, under the specific constraints of sports tasks, we can see that the possibilities of relevant actions are based on behaviors that emerge from the following systems: performance-environment, perception-affordances, 
and affordances-action (Araújo, Hristovski, Seifert, Carvalho, \& Davids, 2017). In this context, when considering the effect of the attack, it is observed that the setting is one of the ecological variables that affects most the opposition faced by the attack (Afonso, Esteves, Thomas, Araújo, \& Mesquita, 2012; Afonso, Mesquita, Marcelino, \& Silva, 2010), where the decision-making by the setter is associated with the setter's own performance (Conejero, Claver, Fernández-Echeverría, \& Moreno, 2017).

However, knowing that most of research in this area has been dedicated to understanding the game in a generalized way and that ecological analysis has little been used in performance analysis (Hileno, García-de-Alcatraz, Busca, Salas, \& Camerino, 2018), the present research aimed to identify how the ecological variables, which conform the situational constraints, influenced the setting, as well as the predictive factors of the effect of the attack in teams ranked between the $1^{\text {st }}$ and $4^{\text {th }}$ place in the Brazilian women's volleyball super league.

\section{Method}

\section{Sample}

The sample consisted of the observations of 768 attacks, considering 10 matches between the teams ranked from the $1^{\text {st }}$ to $4^{\text {th }}$ place in the 20162017 Brazilian Women's Super League. Only the receptions that allowed the organized attack with all actors were considered, due to the limitations of the Kinovea software, considering that only the top shooting was used from the back of the court. This sample is relevant as Brazilian women's volleyball is internationally ranked among the top four national teams (www.fivb.org) and most of its players participate in the Brazilian Super League.

\section{Variables}

Ecological variables. In order to understand how the environmental variables interfere in the setting, we analyzed the distances between the setter and a) the central attacker, b) the central blocker, c) the blocker of position 4 and d) the blocker of position 2. For this purpose, the software Kinovea was used, and for the distances between the setter and position 4, positive values were assigned, considering the location where the setting was performed, while for the distances between the setter and position 2 were assigned negative values. In addition, the respective distances were calculated immediately when the setter touched the ball. The software calibration was done from the center line, the lateral lines and the volleyball net, specifically the distance between the antennas.

Attack tempo. For this analysis we used the instrument proposed by Afonso et al. (2010), where:
- $1^{\text {st }}$ tempo: the attacker jumped during or immediately after the setting, being able to occur a step after the setter;

- $2^{\text {nd }}$ tempo: the attacker performed two or three steps after the setting; and

- $3^{\text {rd }}$ tempo: the attacker waited for the ball to reach the peak of the upward trajectory and only then began the attack.

Type of attack. The type of attack was analyzed according to the instrument proposed by Costa, Ferreira, Junqueira, Afonso, and Mesquista (2011), being:

- Powerful attack: Attack performed with power in descending trajectory.

- Off-speed attack: Attack performed with power control, directing the ball to a vulnerable defensive location.

- Tipping: The ball is contacted at the bottom with the fingertips and directed to a vulnerable defensive site.

Number of blockers. Corresponds to the number of blockers that face the opposing attack. Thus, the following categories were obtained:

- No blocking $(1 \mathrm{x} 0)$ : Corresponds to the absence of blockers due to the excellence of setting.

- Simple blocking (1x1): One-player blocking.

- Double broken blocking $(1+1 \times 1)$ : Corresponds to an uncompacted two-player blocking.

- Double compact blocking (2x1): Corresponds to a two-player blocking, being able to be compacted or not.

- Broken triple blocking $(2+1 x 1)$ : This corresponds to a three-player non-compacted blocking.

- Triple compact blocking (3x1): Corresponds to a three-player compacted blocking.

- No blocking due to the poor quality of the setting (1x0E): Corresponds to the absence of blockers due to the poor quality of the setting.

- Blocking touch: Corresponds to the attack where the ball touched the block. Thus, this variable is dichotomous, making it possible to identify whether or not the ball touched the blocking.

Effect of the attack. To analyze the effect of the attack the instrument was used proposed by Marcelino, Mesquita, and Sampaio (2011), obtaining the following categories:

- Error: Attacker failed by hitting the ball on the net, going out or there has been some infraction in the rules.

- Blocking: Attacker failed in attack due to the opponent's block.

- Defense: The attack action did not result in a terminal action and allowed the opposing counter-attack.

- Point: The attack resulted in a direct point. 


\section{Data collection procedure}

All games were recorded from top perspective, i.e. about 7-9 meters behind the court back line, and the camera was positioned approximately three meters above the ground level for better viewing of scenes. The observers were physical education professionals with at least five years of experience in the function of observational analyzers. For calculation of reliability, $20 \%$ of the actions were re-analyzed, exceeding the reference value of $10 \%$ (Tabachnick \& Fidell, 2013). Cohen's Kappa values for both the inter- and intra-observer reliability were between 0.85 and 1.00 , being higher than the reference value of 0.75 (Fleiss, 2003).

\section{Statistical procedures}

Descriptive analysis was performed and, to identify how the setting location differed in relation to the ecological variables, the ANOVA was used to a factor, and the factor was the location of the setting. In addition, the multinomial logistic analysis was performed for the categorical variables, observing the relation of the independent variables with the dependent variable one-by-one. In this context, the effect of the attack was consid- ered as the dependent variable and independent variables were the type of attack and blocking touch, since the attack tempo and the number of blockers had no association with the effect of the attack. In the treatment of the data the significance value of $5 \%(\mathrm{p} \leq .05)$ was adopted and the SPSS software version 20.0 was used.

\section{Results}

The descriptive analysis of the ecological variables in relation to the location of settings execution is shown in Table 1. The one-way ANOVA showed the location of the setting differed in relation to the distance between the setter and the central attacker $[\mathrm{F}(4.763)=30.903 ; \mathrm{p}<.001]$, the distance between the setter and the central blocker $[\mathrm{F}(4.763)=3.35 ; \mathrm{p}<.01]$ and the distance between the setter and the blocker of position $4[\mathrm{~F}(4.763)=4.05$; $\mathrm{p}<.01]$. Tukey's post-hoc analysis showed that 1) when considering the distance between the setter and the central attacker: the settings for position 6 were different from the other locations, the settings for the central attacker differed from the settings for the opposite attacker and the settings for the opposite attacker differed from settings for the left side

Table 1. Descriptive analysis of the ecological variables regarding the setting place

\begin{tabular}{|c|c|c|c|c|}
\hline Ecological variables & Setting location & $\mathrm{N}$ & $\%$ & Mean $\pm S D$ \\
\hline \multirow{6}{*}{$\begin{array}{l}\text { Distance between the setter and } \\
\text { the central attacker * }\end{array}$} & Central & 298 & $39 \%$ & $0.53 \pm 1.94 \mathrm{~m}$ \\
\hline & Opposite & 147 & $19 \%$ & $2.05 \pm 1.46 \mathrm{~m}$ \\
\hline & Left side & 233 & $30 \%$ & $0.52 \pm 1.93 \mathrm{~m}$ \\
\hline & Back row (6) & 62 & $8 \%$ & $-0.71 \pm 1.72 m$ \\
\hline & Back row (1) & 28 & $4 \%$ & $1.25 \pm 1.97 \mathrm{~m}$ \\
\hline & Total & 768 & $100 \%$ & $0.75 \pm 1.98 \mathrm{~m}$ \\
\hline \multirow{6}{*}{$\begin{array}{l}\text { Distance between the setter and } \\
\text { the central blocker* }\end{array}$} & Central & 298 & $39 \%$ & $1.16 \pm 0.72 \mathrm{~m}$ \\
\hline & Opposite & 147 & $19 \%$ & $1.36 \pm 0.74 m$ \\
\hline & Left side & 233 & $30 \%$ & $1.11 \pm 0.75 \mathrm{~m}$ \\
\hline & Back row (6) & 62 & $8 \%$ & $1.05 \pm 0.88 \mathrm{~m}$ \\
\hline & Back row (1) & 28 & $4 \%$ & $1.36 \pm 0.87 \mathrm{~m}$ \\
\hline & Total & 768 & $100 \%$ & $1.18 \pm 0.76 \mathrm{~m}$ \\
\hline \multirow{6}{*}{$\begin{array}{l}\text { Distance between the setter and } \\
\text { the blocker of position } 4^{*}\end{array}$} & Central & 298 & $39 \%$ & $-0.85 \pm 0.91 \mathrm{~m}$ \\
\hline & Opposite & 147 & $19 \%$ & $-0.67 \pm 0.88 m$ \\
\hline & Left side & 233 & $30 \%$ & $-0.80 \pm 0.96 m$ \\
\hline & Back row (6) & 62 & $8 \%$ & $-1.10 \pm 1.05 m$ \\
\hline & Back row (1) & 28 & $4 \%$ & $-0.34 \pm 1.25 m$ \\
\hline & Total & 768 & $100 \%$ & $-0.80 \pm 0.95 m$ \\
\hline \multirow{6}{*}{$\begin{array}{l}\text { Distance between the setter and } \\
\text { the blocker of position } 2^{*}\end{array}$} & Central & 298 & $39 \%$ & $3.71 \pm 0.84 \mathrm{~m}$ \\
\hline & Opposite & 147 & $19 \%$ & $3.68 \pm 0.91 \mathrm{~m}$ \\
\hline & Left side & 233 & $30 \%$ & $3.64 \pm 0.90 m$ \\
\hline & Back row (6) & 62 & $8 \%$ & $3.74 \pm 1.00 \mathrm{~m}$ \\
\hline & Back row (1) & 28 & $4 \%$ & $3.33 \pm 1.42 \mathrm{~m}$ \\
\hline & Total & 768 & $100 \%$ & $3.67 \pm 0.91 \mathrm{~m}$ \\
\hline
\end{tabular}

Note. ${ }^{*} p<.05$. 
Table 2. Descriptive analysis of game procedures in relation to the effects of the attack

\begin{tabular}{|c|c|c|c|c|c|c|}
\hline \multirow{2}{*}{ Game procedures } & & & \multicolumn{3}{|c|}{ Effect of attack } & \multirow{2}{*}{ Total } \\
\hline & & & Error & Defense & Point & \\
\hline \multirow{4}{*}{ Attack tempo } & \multirow{2}{*}{$1^{\text {st }}$ tempo } & Occurred & 31 & 119 & 143 & 293 \\
\hline & & $\%$ Attack tempo & $10.6 \%$ & $40.6 \%$ & $48.8 \%$ & $100 \%$ \\
\hline & \multirow{2}{*}{$2^{\text {nd }}$ tempo } & Occurred & 62 & 192 & 221 & 475 \\
\hline & & $\%$ Attack tempo & $13.1 \%$ & $40.4 \%$ & $46.5 \%$ & $100 \%$ \\
\hline \multirow{6}{*}{ Type of attack } & \multirow{2}{*}{ Powerful } & Occurred & 82 & 229 & 330 & 641 \\
\hline & & \%Type of attack & $12.8 \%$ & $35.7 \%$ & $51.5 \%$ & $100 \%$ \\
\hline & \multirow{2}{*}{ Off-speed } & Occurred & 6 & 37 & 18 & 61 \\
\hline & & \%Type of attack & $9.8 \%$ & $60.7 \%$ & $29.5 \%$ & $100 \%$ \\
\hline & \multirow{2}{*}{ Tipping } & Occurred & 5 & 45 & 16 & 66 \\
\hline & & \%Type of attack & $7.6 \%$ & $68.2 \%$ & $24.2 \%$ & $100 \%$ \\
\hline \multirow{14}{*}{ Numbers of blockers } & \multirow{2}{*}{$1 \times 1$} & Ocurred & 25 & 83 & 107 & 215 \\
\hline & & $\% n^{\circ}$ of blockers & $11.6 \%$ & $38.6 \%$ & $49.8 \%$ & $100 \%$ \\
\hline & \multirow{2}{*}{$1 \times 1+1$} & Ocurred & 20 & 96 & 115 & 231 \\
\hline & & $\% n^{\circ}$ of blockers & $8.7 \%$ & $41.6 \%$ & $49.8 \%$ & $100 \%$ \\
\hline & \multirow{2}{*}{$1 \times 2$} & Ocurred & 46 & 128 & 127 & 301 \\
\hline & & $\% n^{\circ}$ of blockers & $15.3 \%$ & $42.5 \%$ & $42.2 \%$ & $100 \%$ \\
\hline & \multirow{2}{*}{$1 \times 2+1$} & Ocurred & 0 & 1 & 4 & 5 \\
\hline & & $\% n^{\circ}$ of blockers & $0.0 \%$ & $20.0 \%$ & $80.0 \%$ & $100 \%$ \\
\hline & \multirow{2}{*}{$1 \times 3$} & Ocurred & 0 & 0 & 1 & 1 \\
\hline & & $\% n^{\circ}$ of blockers & $0.0 \%$ & $0.0 \%$ & $100.0 \%$ & $100 \%$ \\
\hline & \multirow{2}{*}{$1 \times 0$} & Ocurred & 0 & 0 & 7 & 7 \\
\hline & & $\% n^{\circ}$ of blockers & $0.0 \%$ & $0.0 \%$ & $100.0 \%$ & $100 \%$ \\
\hline & \multirow{2}{*}{$1 \times 0 \mathrm{E}$} & Ocurred & 2 & 3 & 3 & 8 \\
\hline & & $\% n^{\circ}$ of blockers & $25.0 \%$ & $37.5 \%$ & $37.5 \%$ & $100 \%$ \\
\hline \multirow{4}{*}{ Blocking touch } & \multirow{2}{*}{ Yes } & Ocurred & 52 & 148 & 136 & 336 \\
\hline & & $\%$ Blocking touch & $15.5 \%$ & $44.0 \%$ & $40.5 \%$ & $100 \%$ \\
\hline & \multirow{2}{*}{ No } & Ocurred & 41 & 163 & 228 & 432 \\
\hline & & $\%$ Blocking touch & $9.5 \%$ & $37.7 \%$ & $52.8 \%$ & $100 \%$ \\
\hline
\end{tabular}

Table 3. Predictive factors of the effects of the attack

\begin{tabular}{|c|c|c|c|c|c|c|c|c|c|}
\hline \multirow{2}{*}{\multicolumn{2}{|c|}{ Effect of attack }} & \multirow[b]{2}{*}{$N$} & \multirow[b]{2}{*}{$\%$} & \multirow[b]{2}{*}{ p raw } & \multirow[b]{2}{*}{ OR raw } & \multirow[b]{2}{*}{$\mathrm{p}$ adjusted } & \multirow{2}{*}{ OR adjusted } & \multicolumn{2}{|c|}{$\mathrm{Cl} 95 \%$ for OR } \\
\hline & & & & & & & & $\begin{array}{c}\text { Lower } \\
\text { limit }\end{array}$ & $\begin{array}{l}\text { Upper } \\
\text { limit }\end{array}$ \\
\hline \multirow{5}{*}{$\begin{array}{l}\mathscr{D} \\
\stackrel{\infty}{\Phi} \\
\stackrel{\Phi}{\Phi} \\
0\end{array}$} & Powerful attack & 229 & $73.6 \%$ & 0.017 & 0.310 & $0.025^{\star}$ & 0.327 & 0.123 & 0.872 \\
\hline & Off-speed attack & 37 & $11.9 \%$ & 0.560 & 0.685 & 0.575 & 0.696 & 0.196 & 2.469 \\
\hline & Tipping ${ }^{b}$ & 45 & $14.5 \%$ & & & & & & \\
\hline & Blocking touch & 148 & $47.6 \%$ & 0.16 & 0.72 & 0.616 & 0.883 & 0.544 & 1.435 \\
\hline & No blocking touch ${ }^{\mathrm{b}}$ & 163 & $52.4 \%$ & & & & & & \\
\hline \multirow{5}{*}{$\frac{\vec{C}}{\frac{\mathrm{O}}{0}}$} & Powerful attack & 330 & $90.7 \%$ & 0.66 & 1.26 & 0.315 & 1.717 & 0.599 & 4.924 \\
\hline & Off-speed attack & 18 & $4.9 \%$ & 0.93 & 0.94 & 0.974 & 1.023 & 0.260 & 4.023 \\
\hline & Tipping $^{\mathrm{b}}$ & 16 & $4.4 \%$ & & & & & & \\
\hline & Blocking touch & 136 & $37.4 \%$ & 0.001 & 0.47 & $0.001^{*}$ & 0.440 & 0.274 & 0.707 \\
\hline & No blocking touch ${ }^{\mathrm{b}}$ & 228 & $62.6 \%$ & & & & & & \\
\hline
\end{tabular}

Note. ${ }^{a}$ The reference category for the dependent variable is the attack error. ${ }^{\mathrm{b}}$ The reference category for the independent variable. ${ }^{*} p<.05$. 
attacker; 2) when considering the distance between the setter and the central blocker: the settings for the opposite attacker differed from the settings for the left side attacker; 3 ) when considering the distance between the setter and the blocker of position 4: the settings for the back row attacker of position 6 differed from the settings for the opposite and the back row attacker of position 1 .

The descriptive analysis of game procedures, categorical variables, in relation to the effects of the attack, is represented in Table 2.

The analysis of the predictive factors of the effects of the attack was statistically significant $(\mathrm{x} 2=60.063 ; \mathrm{p}<.0001)$, as shown in Table 3 .

\section{Discussion and conclusions}

The objectives of the present research were to identify how the ecological variables influence the setting, as well as the predictive factors of the effect of the attack when considering the confrontations between the teams ranked between the $1^{\text {st }}$ and $4^{\text {th }}$ place in the women's volleyball super league in Brazil. When analyzing the ecological variables, it was noticed that the location of the setting differed according to the distance between the setter and the central attacker, the distance between the setter and the central blocker, and the distance between the setter and the blocker of position 4. Thus, these results corroborate literature, assuming that ecological theory points out that perception regulates the action according to the information available in the environment (Davids, et al., 2015), as sports performance is understood as a dynamic and complex system (Davids, Araújo, Hristovski, Passos, \& Chow, 2012). In this context, the situational constraints demand athletes' involvement in exploratory behaviors in order to seek and establish effective solutions to respond to the restrictions of competitive performance change (Davids, et al., 2012). In a general analysis, it was observed that the setters adopted setting strategy that forced the central blocker to move by greater displacements, fact that would make the adversary defensive organization difficult. In this way, it is observed that the setter's decision-making is based on the configuration of the blocking that, on the other hand, affects the conformation of the opposing defensive system (Denardi, et al., 2017; Marcelino, Afonso, Moraes, \& Mesquita, 2014; Pinto, Vale, \& Vicente, 2018). Thus, knowing that the blocking is a decisive skill for the victory in volleyball (Oliveira, Valladares, Vaz, \& João, 2016; Peña \& Casals, 2016), setters make decisions based on situational constraints, a fact that leaves the setting unpredictable. Notwithstanding, other variables may influence the setter's decision, such as the attacker quality, but this variable was not in focus in this research. As a practical implication, in relation to the distance of the central attacker, it was noted, for example, that the setting for the back row attacker of position 6 occurred when the central attacker performed a running for the back $1^{\text {st }}$ tempo ball or slide, setting that occurred behind the setter, as well as the setting for the opposite attacker occurred when the central attacker was distant and in front of the setter in a play named inside shoot. In addition, when the central attacker was close to the setter, the settings were for the central or for the left site attacker, differing from the settings performed for the opposite. In this bias, when considering the distance between the setter and the blockers, it was observed that when the central blocker was in front of the setter, it was chosen to set the ball to the opposite and when the blocker of position 4 was close to the setter, suggesting that the blocker would help in blocking the attack performed by the central attacker, it was chosen to set for the opposite attacker in positions 1 or 2.

The descriptive analysis of the categorical variables showed that the use of the second attack tempo, double blocking, powerful attack and the attack where the ball did not touch the blocking were more frequent. These results corroborate the literature that shows the highest occurrence of the $2^{\text {nd }}$ attack tempo (Costa, et al., 2016a, 2016b, 2017b; Conti, et al., 2018; Palao, Santos, \& Ureña, 2007) and double blocking (Ramos, et al., 2017). The analysis of the predictive factors of the effect of the attack showed that the powerful attack reduces the chances of defense (adjusted OR: 0.327). These results corroborate the study by Costa et al. (2017b) that demonstrated the reduction of continuity of game after powerful attacks. However, the results disagree with the study by Conti et al. (2018) who observed an increase in the chances of continuity after powerful attack, specifically when it occurred at position 1. Although there are differences in the predictive factors pointed out in the present research, it is observed that this fact can be related with the specific analysis of the mentioned articles, since they analyzed the attacks performed at positions 4, 2 and 1 of men's super league. In disagreement with the literature, it was observed that the attack tempo and the powerful attack were not shown as predictive factors of the point of attack. The literature shows that the $1^{\text {st }}$ and $2^{\text {nd }}$ attack tempo and powerful attacks predict the point of attack (Costa, Afonso, Barbosa, Coutinho, \& Mesquita, 2014; Costa, et al., 2017b; Stutzig, Zimmermann, Busch, $\&$ Siebert, 2015). Probably, this difference was due to the need of playing with fast balls when facing high quality teams. As in this study, we observed only the confrontations between the four best teams of the championship, playing fast from receptions that allow organized attack with all options of attack and attacking with power were essential factors and were not performance differentiators. It is known that the game played in women's volleyball is of 
the sustaining type, that is, constituted by a greater amount of defense than the game played in men's volleyball (Costa, et al., 2017a; Costa \& Freire, 2017; Mesquita, et al., 2013), it can be suggested that the attacks performed with power aim, initially, at the conquest of the point and, in case this does not occur, it may achieve the limitation of the offensive construction.

Another predictive factor of the effect of the attack was the blocking touch, and there is a reduction in the chances of scoring when the ball touches the blocking (adjusted OR:0.440). These results are in agreement with the literature since the blocking and defense skills are predictive factors of the victory in the game (García-de-Alcaraz, et al., 2015; Oliveira, et al., 2016). In this bias, when the blocking touches the attacked ball, it is easier to set the defense, due to the reduction of attack power, as well as the possibility of the blocking directly score; therefore those factors are predictive of the victory of the game (Oliveira, et al., 2016).

The results of the present research suggest that the decision-making for the setting action, by receptions that allow the organized attack with all actors, is based on the availability of the central attacker for attacking and on the configuration of the blocking, as the setters adopted setting strategies that force the central blocker to move out by greater displacements. It was also observed, in relation to the predictive factors of the effect of the attack, that the powerful attack reduces the chances of defense and the blocking touch reduces the chances of scoring by the attack. Although the objective of this study was limited to investigating the predictive factors of the effect of the attack and how the ecological variables influence the setting, it is hoped that the results found may contribute to a better understanding of volleyball teams' success. In addition, this study has, as a practical implication, the possibility of understanding tactical strategies of setting used in the confrontation of the high level teams of the Brazilian super league, allowing, from this knowledge, new tactical configurations seeking the unpredictability in the setting. As a suggestion for future research, one must investigate whether such evidence exists in male volleyball and in international high-level volleyball competitions.

\section{References}

Afonso, J., Esteves, F., Thomas, L., Araújo, R., \& Mesquita, I. (2012). Tactical determinants of setting zone in elite men's volleyball. Journal of Sport Science and Medicine, 11(1), 64-70.

Afonso, J., Mesquita, I., Marcelino, J., \& Silva, J. (2010). Analysis of the setter's tactical action in high performance women's volleyball. Kinesiology, 42(1), 82-89.

Araújo, D., Davids, K., \& Hristovski, R. (2006). The ecological dynamics of decision making in sport. Psychology of sport and exercise, 7(6), 653-676.

Araújo, D., Hristovski, R., Seifert, L., Carvalho, J., \& Davids, D. (2017). Ecological cognition: Expert decision-making behaviour in sport. International Review of Sport and Exercise Psychology, 10, 1-25.

Barreira, J., \& Silva, C.E. (2016). National teams in Women's Soccer World Cup from 1991 to 2015: Participation, performance and competitiveness. Journal of Physical Education and Sport, 16(3), 795-799.

Clemente, F.M., Martins, F.M.L., Mendes, R.S., \& Silva, F. (2016). Social network measures to match analysis in soccer: A survey. Journal of Physical Education and Sport, 16(3), 823-830.

Conejero, M., Claver, F., Fernández-Echeverría, C., \& Moreno, M.P. (2017). Relationship between decision-making and performance in game actions in volleyball. European Journal of Human Movement, 39, 82-95.

Conti, G., Freire, A., Evangelista, B., Pedrosa, G., Ugrinowitsch, H., \& Castro, H. (2018). Brazilian high-level men's volleyball: Characterization of the attack performed by the opposite player. Kinesiology, 50(2), 10-17.

Costa, G., Afonso, J., Barbosa, R., Coutinho, P., \& Mesquita, I. (2014). Predictors of attack efficacy and attack type in high-level Brazilian women's volleyball. Kinesiology, 46(2), 242-248.

Costa, G.C.T, Castro, H.O., Evangelista, B.F., Malheiros, L.M., Greco, P.J., \& Ugrinowitsch, H. (2017b). Predicting factors of zone 4 attack in volleyball. Perceptual and Motor Skills, 124(3), 621-633.

Costa, G.C.T., Ceccato, J.S., Oliveira, A.S., Evangelista, B.F.B., Castro, H.O., \& Ugrinowitsch, H. (2016b). Men's highlevel volleyball: Association between game actions on the side-out. Journal of Physical Education, 27(1), 1-15.

Costa, G.C.T., Ferreira, N., Junqueira, G., Afonso, J., \& Mesquita, I. (2011). Determinants of attack tactics in youth male elite volleyball. International Journal of Performance Analysis in Sport, 11(1), 96-104.

Costa, G.D.C.T., \& Freire, A. (2017). Voleibol feminino de alto nível: análise do ataque na Superliga Feminina [Highlevel women's volleyball: analysis of the attack in the Women's Super League. In Portuguese.] Revista Brasileira de Educação Física e Esporte, 31(2), 365-372.

Costa, G.C.T., Maia, M.P., Capuzzo, J., Evangelista, B., Freire, A., Nora, F.G., Campos, M.H., \& Ugrinowitsch, H. (2016a). Offensive structuring in men's high-level volleyball: Analysis of the attack zone. Brazilian Journal of Kinanthropometry and Human Performance, 18(5), 611-619. 
Costa, G.D.C.T., Maia, M.P., Rocha, A.C.R., Martins, L.R., Gemente, F.R.F., Campos, M.H., Milistetd, M., \& Freire, A.B. (2017a). Association between effect of reception and game procedures in high-level Brazilian volleyball: The case of the women's "Superliga" champion team. Brazilian Journal of Kinanthropometry and Human Performance, 19(6), 663-675.

Davids, K., Araújo, D., Hristovski, R., Passos, P., \& Chow, J.Y. (2012). Ecological dynamics and motor learning design in sport. In A.M. Williams \& N. Hodges (Eds.), Skill acquisition in sport: Research, theory and practice (2nd ed.) (pp. 112-130). London: Routledge.

Davids, K., Araújo, D., Seifert, L., \& Orth, D. (2015). Expert performance in sport: An ecological dynamics perspective. In J. Baker \& D. Farrow (Eds.), Routledge handbook of sport expertise (pp. 130-144). London: Routledge.

Denardi, R.A., Clavijo, F.A.R., Oliveira, T.A.C., Travassos, B., Tani, G., \& Corrêa, U.C. (2017). The volleyball setter's decision-making on attacking. International Journal of Performance Analysis in Sport, 17(4), 442-457.

Eom, H.J., \& Schutz, R.W. (1992). Statistical analyses of volleyball team performance. Research Quarterly for Exercise and Sport, 63(1), 11-18.

Fleiss, J.L. (2003). Statistical methods for rates and proportions (3rd ed.). Hoboken, NJ: Wiley Interscience.

García-de-Alcaraz, A., \& Marcelino, R. (2017). Influence of match quality on men's volleyball performance at different competition levels. International Journal of Performance Analysis in Sport, 17(4), 394-405.

García-de-Alcaraz, A., Ortega, E., \& Palao, J.M. (2015). Effect of age group on male volleyball players' technicaltactical performance profile for the spike. International Journal of Performance Analysis in Sport, 15(2), 668-686.

Hileno, R., García-de-Alcaraz, A., Buscà, B., Salas, C., \& Camerino, O. (2018). What are the most widely used and effective attack coverage systems in men's volleyball? Journal of Human Kinetics, 62, 111-121.

Hughes, M., \& Bartlett, R.M. (2002). The use of performance indicators in performance analysis. Journal of Sports Science, 20, 739-754.

Marcelino, R., Afonso, J., Moraes, J.C., \& Mesquita, I. (2014). Determinants of attack players in high-level men's volleyball. Kinesiology, 46(2), 234-241.

Marcelino, R., Mesquita, I., \& Sampaio, J. (2011). Effects of quality of opposition and match status on technical and tactical performances in elite volleyball. Journal of Sports Sciences, 29(7), 733-741.

Mesquita, I., Palao, J.M., Marcelino, R., \& Afonso, J. (2013). Performance analysis in indoor volleyball and beach volleyball. In T. McGarry, P. O’Donoghue \& J. Sampaio (Eds.), Routledge handbook of sports performance analysis (pp. 367-379). London: Routledge.

Oliveira, A.O.G.F., Valladares, N., Vaz, L.M.T., \& João, P.V. (2016). Evaluation of scoring skills and non-scoring skills in the Brazilian SuperLeague women's volleyball. Montenegrin Journal of Sports Science and Medicine, 5(2), 25-31.

Palao, J.M., Santos, J.A., \& Ureña, A. (2007). Effect of the manner of spike execution on spike performance in volleyball. International Journal of Performance Analysis in Sport, 2(Suppl. 1), 126-138

Paulo, A., Davids, K., \& Araújo, D. (2017). Co-adaptation of ball reception to the serve constrains outcomes in elite competitive volleyball. International Journal of Sports Science and Coaching, 13(2), 253-261.

Peña, J., \& Cassals, M. (2016). Game-related performance factors in four European Men's Professional Volleyball Championships. Journal of Human Kinetics, 53(1), 223-230.

Pinto, R., Vale, S., \& Vicente, J.P. (2018). The action of the middle blocker according to the opposing offensive organization in volleyball. Journal of Sports Science, 6, 178-185.

Ramos, A., Coutinho, P., Silva, P., Davids, K., Guimarães, E., \& Mesquita, I. (2017). Entropy measures reveal collective tactical behaviours in volleyball teams: How variability and regularity in game actions influence competitive rankings and match status. International Journal of Performance Analysis in Sport, 17(6), 848-862.

Stutzig, N., Zimmermann, B., Busch, D., \& Siebert, T. (2015). Analysis of game variables to predict scoring and performance levels in elite men's volleyball. International Journal of Performance Analysis in Sport, 15(3), 816-829.

Tabachnick, B., \& Fidell, L. (2013). Using multivariate statistics (6th ed.). Boston: Allyn \& Bacon.

Submitted: January 27, 2019

Accepted: April 16, 2020

Published Online First: Novemeber 24, 2020

Correspondence to:

Gustavo Ferreira Pedrosa, Ph.D.

Centro de Instrução e Adaptação da Aeronáutica,

Lagoa Santa/Minas Gerais, Brazil

Phone: +55 31 2112-9274

E-mail: gustavofpedrosa@gmail.com 